\title{
Metered dose inhaler and nebuliser in acute asthma
}

\author{
Yung-Zen Lin, Kue-Hsiung Hsieh
}

\begin{abstract}
One hundred and eleven children with acute asthma were studied to compare delivery of terbutaline by either a metered dose inhaler (MDI) with a valved holding chamber or a nebuliser driven by air. Eligible patients were randomised; the MDI group received three puffs $(0.75 \mathrm{mg})$ of terbutaline and the nebuliser group received $2 \mathrm{ml}(5.0 \mathrm{mg})$ terbutaline solution diluted with $2 \mathrm{ml} 0.9 \%$ saline for inhalation over 10 minutes. Patients were evaluated by spirometry, pulse oximetry, and clinical severity scoring system at baseline and again 15 minutes after the beginning of treatment. The baseline data of the two groups were not significantly different. All parameters of spirometry, except the peak expiratory flow (PEF) for the nebuliser group, and clinical severity score for both groups significantly improved after terbutaline treatment. Compared with the nebuliser group, the MDI group after treatment had better mean (SD) oxygen saturation $\left(\mathrm{SaO}_{2} ; 96.82(1.63) \%\right.$ v $\left.95.44(1.88) \%\right)$, frequency of oxygen desaturation $(23.2 \% v$ 47.3\%), absolute increase of PEF (32.6 $(37 \cdot 7) 1 / \min v 10.2(34 \cdot 7) 1 / \mathrm{min})$, and $\mathrm{SaO}_{2}$ $(0.54(1.64) \% v-0.47(1.84) \%)$. There was also a mean (SD) per cent increase of forced expiratory volume in one second $(22.9(21 \cdot 0) \%$ v 15.4 (16.1)\%), PEF $(27 \cdot 7$ $(38.4) \%) v 7.7(25 \cdot 1) \%)$, and $\mathrm{SaO}_{2}(0.58$ $(1.72) \% v-0.47(1.93) \%)$. In conclusion, aerosol treatment by MDI (with a valved holding chamber) in this study proved to be superior to nebuliser treatment in terms of $\mathrm{SaO}_{2}$ and some measurements of spirometry. Respiratory therapists working with children with severe asthma should be aware of the possibility of oxygen desaturation, especially when using room air as the driving gas for nebulisation. (Arch Dis Child 1995; 72: 214-218)
\end{abstract}

Keywords: metered dose inhaler, nebuliser, terbutaline, acute asthma.

Departments of Paediatrics, Taipei Municipal Chung Hsiao Hospital $\mathrm{Y}-\mathrm{Z}$ Lin

National Taiwan University Hospital, Taipei, Taiwan, ROC $\mathrm{K}-\mathrm{H}$ Hsieh

Correspondence to: Dr Yung-Zen Lin Department of Paediatrics, Taipei Municipal Chung Hsiao Hospital, No 87, Tung Ter Teh Road, Taipei 11502, Taiwan, ROC.

Accepted 12 December 1994 adrenaline and have become the mainstay of treatment for acute asthma because they show fewer side effects and equivalent bronchodilation. ${ }^{1-3}$ These aerosols may be administered by metered dose inhaler (MDI) or nebuliser, thus not only reducing the adverse effects from oral or parenteral administration, but also avoiding patient discomfort when treating a paediatric population.
Although effective, the use of nebulised $\beta_{2}$ agonists has various disadvantages. Nebulisers are expensive, cumbersome to use, and need outside electric power. The MDI is a convenient device to use for quick relief of acute airway obstruction, but there can be problems of coordination between actuation and inhalation, particularly in small children who may not comprehend the instructions or whose hand-inspiration coordination may not yet be adequately developed. ${ }^{4}$ Attachment to a pressurised $\beta_{2}$ aerosol of a holding chamber with a one way valve system has been shown to increase the deposition of aerosol particles in the lungs and decrease upper airway aerosol deposition, as does unaided use of an MDI. ${ }^{6}$ This development has resolved many of the technical problems that commonly occurred in asthmatic children using an unaided MDI for treatment.

Some recent reports have suggested there is little difference between the MDI and nebuliser methods of treatment in asthmatic patients. ${ }^{8-13}$ Most of these reports measured only forced vital capacity (FVC) and forced expiratory volume in one second $\left(\mathrm{FEV}_{1}\right)^{8-11}$; several reports also measured the dyspnoea score. ${ }^{12} 13$ All of the studies used oxygen as the driving gas in nebuliser treatment, and therefore the oxygen saturation $\left(\mathrm{SaO}_{2}\right)$ between the two methods was not comparable because no oxygen was supplied in MDI treatment. It is important that $\mathrm{SaO}_{2}$ is measured because, although there have been a few reports describing the occurrence of hypoxaemia or oxygen desaturation after inhalation of selective $\beta_{2}$ adrenergic agonists, ${ }^{31415}$ oxygen is not routinely given in nebuliser treatment of acute asthmatics here or in many other paediatric emergency institutions, ${ }^{16}$ even for those with severe asthma. Also it is usually cumbersome and sometimes dangerous to provide oxygen at home because of inflammability. To our knowledge, $\mathrm{SaO}_{2}$ has not been studied when room air is used as the driving gas for both treatments.

This study used a clinical scoring system, spirometer, and pulse oximeter to compare the clinical response, $\mathrm{SaO}_{2}$, and bronchodilator response to terbutaline as delivered by an MDI (with a valved holding chamber) or an air compressor nebuliser driven by room air in asthmatic children with acute attacks. agonists have largely replaced the injection
Patients and methods PATIENTS

Patients who presented to the emergency department and paediatric allergy clinic of the Taipei Municipal Chung Hsiao Hospital with 
a diagnosis of acute asthma, or of acute exacerbation of chronic asthma, were enrolled in the study. The diagnosis of asthma was based on American Thoracic Society standards. ${ }^{17}$ Patients were eligible for study if they were at least 5 years of age and able to perform spirometry. Patients with complications of pneumonia, congestive heart failure, foreign body aspiration, or bronchopulmonary dysplasia were excluded. Patients who had received any aerosolised $\beta$ agonist within six hours before presentation were also excluded.

\section{TREATMENT PROTOCOLS}

The inhalation treatment was performed after measurements of baseline spirometry, $\mathrm{SaO}_{2}$ pulse rate, and clinical severity scores. The MDI and nebuliser treatments alternated with each other, week by week, for successive eligible patients. The MDI group received three puffs $(0.75 \mathrm{mg})$ of terbutaline (Bricanyl, Astra) inhaled through a holding chamber with facemask (AeroChamber, Trudell Medical). Patients were taught to take three deep breaths after each actuation. The nebuliser group received $2.5 \mathrm{mg}(2 \mathrm{ml})$ of terbutaline solution (Bricanyl, Astra) diluted with $2 \mathrm{ml}$ normal saline ( $4 \mathrm{ml}$ in total) delivered by an air compressor nebuliser (Pulmo-Aide, Model No 5610D; DeVilbiss), driven by air at a flow rate of $8 \mathrm{l} /$ minute, inhaled through a mouthpiece. Patients were instructed to take three deep breaths slowly. When tapping the solution container did not result in further aerosolisation, the mouthpiece was removed from the patient. This procedure usually took 10 minutes. Measurements of baseline spirometry, $\mathrm{SaO}_{2}$, pulse rate, and clinical severity scores were repeated 15 minutes after the beginning of the inhalation treatment.

\section{MEASUREMENTS}

Spirometry

All eligible patients had spirometry performed including FVC, $\mathrm{FEV}_{1}$, peak expiratory flow (PEF), and forced expiratory flow $25-75 \%$ $\left(\mathrm{FEF}_{25-75 \%}\right)$. All tests were performed using standard spirometry (Vitalograph Compact, Cat No 42.000; Vitalograph). The FVC, $\mathrm{FEV}_{1}, \mathrm{PEF}$, and $\mathrm{FEF}_{25-75 \%}$ values of at least

Table 1 Demographic characteristics of patients before treatment; values are mean (SD)

\begin{tabular}{|c|c|c|}
\hline & $\begin{array}{l}M D I \text { group } \\
(n=56)\end{array}$ & $\begin{array}{l}\text { Nebuliser group } \\
(n=55)\end{array}$ \\
\hline $\begin{array}{l}\text { Sex }(\mathbf{M} / \mathbf{F}) \\
\text { Age (years) } \\
\text { Range }\end{array}$ & $\begin{array}{l}40 / 16 \\
8 \cdot 1(2 \cdot 6) \\
5-16\end{array}$ & $\begin{array}{l}35 / 20 \\
8 \cdot 4(3 \cdot 0) \\
5-15\end{array}$ \\
\hline $\begin{array}{l}\text { No who had taken oral } \\
\text { bronchodilators before } \\
\text { study }\end{array}$ & 14 & 16 \\
\hline 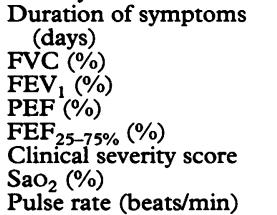 & $\begin{array}{c}3 \cdot 05(2 \cdot 20) \\
74 \cdot 75(24 \cdot 31) \\
65 \cdot 74(20 \cdot 33) \\
57 \cdot 56(19 \cdot 60) \\
57 \cdot 53(28 \cdot 02) \\
4 \cdot 86(1 \cdot 80) \\
96 \cdot 29(1 \cdot 94) \\
110(19)\end{array}$ & $\begin{array}{c}3 \cdot 12(2 \cdot 17) \\
71 \cdot 63(21 \cdot 24) \\
63 \cdot 14(20 \cdot 50) \\
60 \cdot 30(21 \cdot 32) \\
55 \cdot 63(28 \cdot 77) \\
4 \cdot 60(1 \cdot 83) \\
95 \cdot 91(1 \cdot 96) \\
111(20)\end{array}$ \\
\hline
\end{tabular}

*Still within the pharmacological effect of the drugs.

The spirometric data are expressed as $\%$ predicted value. three consecutive efforts were determined using the curve having the best $\mathrm{FEV}_{1}$ as defined by the American Thoracic Society. ${ }^{18}$ The values were expressed as percentage of the predicted normal values for height and sex.

\section{$\mathrm{SaO}_{2}$ and pulse rate}

$\mathrm{SaO}_{2}$ and pulse rate were recorded using a pulse oximeter (model Accusat, Datascope) and measured through the nail bed of the index finger. $\mathrm{SaO}_{2}$ values were accepted only if they were stable for 5 seconds on the pulse oximeter screen during reading.

\section{Evaluation of clinical response}

The clinical severity scores of patients were evaluated according to Tal et al. ${ }^{19}$ The parameters included respiratory rate, wheezing, cyanosis, and accessory respiratory muscle utilisation. Each item was scored from 0-3 and evaluated by the same paediatrician. The scores were then added to give a single clinical severity score.

\section{STATISTICS}

Results were expressed as mean (SD). The two tailed Wilcoxon signed rank sum test was used for statistical analysis of the clinical severity scores. The two tailed Student's $t$ test was used for statistical analysis of spirometry and pulse oximetry at baseline and after treatment, with mean absolute and per cent increases from baseline. Paired tests were used within the same groups and unpaired tests, between groups. The sex and medication and comparative frequency of the decrease of $\mathrm{SaO}_{2}$ after treatment were assessed by the $\chi^{2}$ test. A $p$ value of less than 0.05 was considered statistically significant.

\section{Results}

One hundred and seventeen patients initially enrolled into this study were randomised into the two groups (60 to the MDI, 57 to the nebuliser). Six patients did not complete the study: four in the MDI group were withdrawn because they were either frightened by being covered with the AeroChamber mask or unable to comply with mouth breathing instructions and two in the nebuliser group were excluded because they refused to inhale the foggy aerosol. Table 1 shows demographic characteristics of the 111 patients completing the study. Patients randomised to the two groups were well matched at baseline for age, sex, FVC, $\mathrm{FEV}_{1}, \mathrm{PEF}, \mathrm{FEF}_{25-75 \%}, \mathrm{SaO}_{2}$, pulse rate, and clinical severity score.

The results from both groups, after terbutaline treatment, are shown in table 2. All parameters (except the PEF for the nebuliser group) of spirometry and clinical severity score for both groups significantly improved after terbutaline treatment, as did the $\mathrm{SaO}_{2}$ for the MDI group. The mean value of $\mathrm{SaO}_{2}$ for the nebuliser group decreased after treatment but was not statistically significant $(p=0.0627)$. 
Table 2 Clinical and laboratory parameters after treatment; values are mean (SD)

\begin{tabular}{lccl}
\hline & MDI group & Nebuliser group & $p$ Value $\dagger$ \\
\hline FVC (\%) & $86 \cdot 60(24 \cdot 51)^{\star}$ & $82 \cdot 02(22 \cdot 80)^{\star}$ & NS \\
FEV $_{1}(\%)$ & $78 \cdot 80(21 \cdot 58)^{\star}$ & $71 \cdot 80(22 \cdot 08)^{\star}$ & NS \\
PEF $(\%)_{\mathrm{FEF}_{25}-75 \% \text { (\%) }}$ & $70 \cdot 10(21 \cdot 24)^{\star}$ & $62 \cdot 79(20 \cdot 25)$ & NS \\
Clinical severity score $_{\mathrm{SaO}_{2}(\%)}$ & $75 \cdot 24(31 \cdot 25)^{\star}$ & $63 \cdot 82(28 \cdot 83)^{\star \star}$ & NS \\
Pulse rate (beats/min) & $2 \cdot 27(1 \cdot 83)^{\star}$ & $2 \cdot 53(1 \cdot 93)^{\star}$ & NS \\
& $96 \cdot 82(1 \cdot 63)^{\star \star \star}$ & $95 \cdot 44(1 \cdot 88)$ & $<0.0001$ \\
\hline
\end{tabular}

NS: not significant

tp Value computed by two tailed unpaired Student's $t$ test

${ }_{\star} \mathrm{p}<0.0001,{ }^{\star \star} \mathrm{p}=0.0010 ;{ }^{\star \star \star} \mathrm{p}=0.0177$ when compared with values of the same group before treatment by paired Student's $t$ test.

The mean pulse rate showed almost no change. Compared with the MDI group, the $\mathrm{SaO}_{2}$ of the nebuliser group after treatment was significantly lower. Otherwise, there was no statistically significant difference between the two groups in spirometry, clinical severity score, or pulse rate.

Table 3 demonstrates the mean absolute and per cent increase of spirometric results and $\mathrm{SaO}_{2}$ from baseline after terbutaline treatment. The mean absolute increase of PEF and $\mathrm{SaO}_{2}$ for the MDI group, and the mean per cent increase of $\mathrm{FEV}_{1}, \mathrm{PEF}$, and $\mathrm{SaO}_{2}$ were significantly higher than those for the nebuliser group. The mean absolute and per cent increase of $\mathrm{SaO}_{2}$ for the nebuliser group was negative. Thirteen $(23 \%)$ children in the MDI group and $26(47 \%)$ in the nebuliser group had a decreased $\mathrm{SaO}_{2}$ after treatment $(\mathrm{p}=0 \cdot 0079)$.

\section{Discussion}

The results of this study showed that both MDI and nebuliser treatment were effective in treating clinical severity and airway obstruction in children with acute asthma, but the MDI (with a holding chamber) method was better than the nebuliser method particularly for improvement of the $\mathrm{SaO}_{2}$ and in some measurements of spirometry.

In the past, bronchodilation achieved by nebulisation was considered to be greater than that obtained by an MDI, and therefore the former was the treatment of choice for in hospital treatment of asthma. ${ }^{20}$ However, recent reports have suggested that there is little difference between these two forms of treatment in asthmatic patients. ${ }^{8-13}$ Although Olivenstein et al found significantly greater absolute increases from baseline for $\mathrm{FEV}_{1}$ and $\mathrm{FEF}_{25-75 \%}$ with the MDI compared with the ultrasonic nebuliser, ${ }^{21}$ and Hodder et al reported superior bronchodilation in the $\mathrm{MDI}$ group compared with the nebulisation group, ${ }^{22}$ the degree of bronchodilation achieved in

Table 3 Mean absolute and per cent increase of spirometric results and $\mathrm{SaO}_{2}$ from baseline after terbutaline treatment; values are mean (SD)

\begin{tabular}{|c|c|c|c|c|c|c|}
\hline & \multicolumn{3}{|c|}{ Mean absolute increase } & \multicolumn{3}{|c|}{ Mean per cent increase } \\
\hline & $M D I$ & Nebuliser & p Value ${ }^{\star}$ & $M D I$ & Nebuliser & $p$ Value \\
\hline $\begin{array}{l}\text { FVC } \\
\mathrm{FEV}_{1} \\
\mathrm{PEF} \\
\mathrm{FEF}_{25-75 \%} \\
\mathrm{SaO}_{2}\end{array}$ & $\begin{array}{c}0.23(0.34) \\
0.23(0.21) \\
32.6(37.7) \\
0.39(0.50) \\
0.54(1.64)\end{array}$ & $\begin{array}{c}0.21(0.23) \\
0.17(0.18) \\
10.2(34.7) \\
0.22(0.41) \\
-0.47(1.84)\end{array}$ & $\begin{array}{l}\text { NS } \\
\text { NS } \\
0.0016 \\
\text { NS } \\
0.0029\end{array}$ & $\begin{array}{c}19.9(25.2) \\
22.9(21.0) \\
27.7(38.4) \\
82.5(298.4) \\
0.58(1.72)\end{array}$ & $\begin{array}{c}16 \cdot 7(18 \cdot 1) \\
15 \cdot 4(16 \cdot 1) \\
7 \cdot 7(25 \cdot 1) \\
26 \cdot 5(48 \cdot 3) \\
-0 \cdot 47(1 \cdot 93)\end{array}$ & $\begin{array}{l}\text { NS } \\
0.0391 \\
0.0017 \\
\text { NS } \\
0.0031\end{array}$ \\
\hline
\end{tabular}

^Computed by two tailed unpaired Student's $t$ test. asthmatic patients was later demonstrated to be a reflection of the dose of bronchodilator administered, not of the mode of administration. ${ }^{1223}$ The equivalent response dose of MDI to nebuliser has been reported to be between $1: 1$ to $1: 12 \cdot 5.121323-26$ This wide range reflects the variability in dose delivered to the lungs by different nebulising systems. In this study design, $0.75 \mathrm{mg}$ of terbutaline given by MDI was compared with $5 \mathrm{mg}$ of terbutaline given by nebuliser; this is an equivalent dosage for bronchodilation, according to the recent report of Colacone et al. ${ }^{12}$ They also used the AeroChamber for holding and compared its effects with the air compressor nebuliser. Most of the studies measured only FVC and $\mathrm{FEV}_{1},{ }^{8-11}$ with a few reports also measuring the dyspnoea score. ${ }^{12} 13$ In this study, more parameters $\left(\mathrm{SaO}_{2}\right.$, pulse rate, FVC, $\mathrm{FEV}_{1}$, $\mathrm{PEF}, \mathrm{FEF}_{25-75 \%}$, and clinical severity score) were compared and better results were found in the MDI group. Compared with the recent study by Kerem et al, who found spacers and nebulisers were equally effective means of delivering $\beta_{2}$ agonists to children with acute asthma, ${ }^{13}$ our patients were of smaller mean age and had higher mean baseline per cent predicted $\mathrm{FEV}_{1}$ and mean $\mathrm{SaO}_{2}$. A clinical diagnosis of an acute asthma attack in patients with wheezing cough was our major inclusion criteria rather than an initial $\mathrm{FEV}_{1}$ between $20 \%$ and $70 \%$ of the predicted value. Moreover, we compared the MDI group with the nebuliser group 15 minutes after the beginning of treatment, not timing from the termination of treatment. Many of these factors could have an influence on the study results. While the superior bronchodilation effect of the MDI found in this study may reflect only the different doses of terbutaline administered or different timing at the evaluation after treatment, the lower $\mathrm{SaO}_{2}$ found with the nebuliser compared with that of the MDI invites attention.

The causes for oxygen desaturation have been suggested by some authors to result from a change in the ventilation-perfusion ratio, 2728 and by others to be a change in $\mathrm{pH}$ and osmolality in response to the nebulised solutions, ${ }^{29-31}$ which have been well documented to produce bronchoconstriction in asthmatic subjects. ${ }^{32} 33$ The MDI method with a valved holding chamber removes the large aerosol particles, which often deposit themselves in the mouth and throat while allowing the smaller treatment particles to pass into the lungs. This provides effective treatment and helps to reduce unwanted side effects. By increasing effective pulmonary aerosol deposition, ${ }^{67}$ and removing unwanted upper airway deposition, the former provided more effective bronchodilation and the latter reduced cardiovascular effect, and this could make ventilation-perfusion mismatch less likely. Moreover, MDI administration gave no problem with osmotic change during nebuliser treatment. ${ }^{30} 31$ The nebuliser group were more vulnerable to temperature drop, ${ }^{34}$ acidity, and osmolality change of the nebulised solution. All these factors can decrease the bronchodilation effect of terbutaline. O'Callaghan $e t a l$, in their study 
in infants, found nebulised salbutamol induced bronchoconstriction was greatest at five minutes after nebulisation, lasting for up to 15 minutes. ${ }^{29}$ Prendiville et al also reported that the hypoxic effect of salbutamol and the decline in forced expiratory flow rate was still present 20 minutes after nebulisation. ${ }^{35}$ Therefore, our nebulised patients were probably influenced by the hypoxic effect when they were measured for $\mathrm{SaO}_{2}$, which was usually masked by the oxygen supply in the studies using oxygen as the driving gas. ${ }^{8-13}$

The possibility that there might also be a decrease in $\mathrm{SaO}_{2}$ very soon after administration of terbutaline by MDI that was missed by our later measurements causes concern. Harris used salbutamol given by MDI, without a holding chamber, in asthmatic patients and detected the phenomenon of hypoxaemia even at 30 minutes after treatment. ${ }^{27}$ Altogether $23 \%$ of our group using the $\mathrm{MDI}$ had their $\mathrm{SaO}_{2}$ decreased after treatment. In general, however, the decrease was less frequent and severe than that of the nebuliser group. The two methods of aerosol administration were quite different. It took less than one minute for the MDI and about 10 minutes for the nebuliser to complete the treatment. The drug effect started soon after MDI administration but did so by accumulation during the nebulisation. We made the comparison 15 minutes after the beginning (not termination) of terbutaline administration because, on the one hand, we attempted to study the difference after the two groups of patients had spent the same time in respiratory treatment room; on the other hand, in our previous study with a similar design, the $\mathrm{SaO}_{2}$ of nebulised patients significantly improved as early as two minutes after the beginning of terbutaline nebulisation. ${ }^{36}$ This led us to speculate that the improvement of pulmonary function started before the end of nebulisation. We therefore made comparison timings from the beginning of treatment. However, a further study of serial $\mathrm{SaO}_{2}$ monitoring, with timing from the beginning of administration of the drug and until at least 30 minutes after the termination of treatment for both groups, is needed. Although the mean absolute decrease of $\mathrm{SaO}_{2}$ in the nebuliser group was only $0.47 \%$, this treatment might endanger the life of high risk asthmatic patients. Therefore, oxygen should, if possible, be chosen as the driving gas in treating severe asthmatic patients by nebuliser.

In addition to having less adverse effects, MDI treatment with a valved holding chamber can be very easily performed by patients themselves, or with help from physicians or parents if the patients are too young. This is therefore a portable, convenient method to provide quick symptom relief during an acute asthmatic attack and thus prevents it progressing. Frequent visits to an emergency room may be avoided. Another advantage is that the substitution of MDI treatment for nebuliser treatment is the time and finance savings ${ }^{37} 38$; this is beneficial for health care providers and receivers, as well as for health insurance providers.

In conclusion, aerosol treatment by $\mathrm{MDI}$ (with a valved holding chamber) in this study is superior to nebuliser treatment in terms of $\mathrm{SaO}_{2}$ and some spirometric measurements. In patients with severe asthma inhaled $\beta_{2}$ bronchodilators should be given with caution and there should be an awareness of the possibility of oxygen desaturation, especially when room air is used as the driving gas.

The authors express their thanks to Dr Ping-Ing Lee of National Taiwan University Hospital for his help in statistical analysis of the material, and to Dr Chun-Yuan Chu and Dr analysis of the material, and to Dr Chun-Yuan Chu and Dr
Ching-Jong Shyu for their technical assistance in pulmonary Ching-Jong Shyu for their technical
function tests and pulse oximetry.

1 Tinkelman DG, Vanderpool GE, Carroll MS, et al. Comparison of nebulized terbutaline and subcutaneous epinephrine in the treatment of acute asthma. Ann Allergy 1983; 50: 398-401.

2 Pliss LB, Gallagher EJ. Aerosol vs injected epinephrine in acute asthma. Ann Emerg Med 1981; 10: 353-5.

3 Becker AB, Nelson NA, Simons FER. Inhaled salbutamol (albuterol) vs injected epinephrine in the treatment of acute asthma in children. $\mathcal{F}$ Pediatr 1983; 102: 465-9.

4 Epstein SW, Manning CPR, Ashley MJ, Corey PN. Survey of the clinical use of pressurized aerosol inhalers. Can Med Assoc F 1979; 120: 813-6.

5 MacFarlane JT, Lane DJ. Irregularities in the use of regular aerosol inhalers. Thorax 1980; 35: 477-8.

6 Newman SP, Millar AB, Lennard-Jones TR, Moren F, Clarke SW. Improvement of pressurized aerosol deposition with Nebuhaler spacer device. Thorax 1984; 39: 935-41.

7 Dolovich M, Ruffin R, Corr D, Newhouse $M$. Clinical evaluation of a simple demand inhalation MDI aerosol delivery device. Chest 1983; 84: 36-41.

8 Salzman GA, Steele MT, Pribble JP, Elenbaas RM, Pyszczynski DR. Aerosolized metaproterenol in the treatment of asthmatics with severe airflow obstruction: comparison of two delivery methods. Chest 1989; 95: 1017-20.

9 Turner JR, Corkery KJ, Eckman DE, Gelb AM, Lipavsky A, Sheppard D. Equivalence of continuous flow nebulizer and metered dose inhaler with reservoir bag for treatment of acute airflow obstruction. Chest 1988; 93: 476-81.

10 Fuglsang G, Pedersen S. Comparison of nebuhaler and nebulizer treatment of acute severe asthma in children. European fournal of Respiratory Diseases 1986; 69: 109-13.

11 Berenberg MJ, Cupples LA, Baigelman W, Pearce L. Comparison of metered-dose inhaler attached to an aerochamber with an updraft nebulizer for the administration of metaproterenol in hospitalized patients. $\mathcal{F}$ Asthma 1985; 22: 87-92.

12 Colacone A, Afilalo M, Wolkove N, Kreisman H. A comparison of albuterol administered by metered dose inhaler (and holding chamber) or wet nebulizer in acute asthma. Chest 1993; 104: 835-41.

3 Kerem E, Levison $\mathrm{H}$, Schuh S, et al. Efficacy of albuterol administered by nebulizer versus spacer device in children with acute asthma. $\mathcal{F}$ Pediatr 1993; 123: 313-7.

14 Fedrick J, Baldwin JA. Comparison of intravenous and nebulised salbutamol in initial treatment of severe asthma. $B M 7$ 1978; 14: 84 .

15 Tal A, Pasterkamp H, Leahy F. Arterial oxygen desaturation following salbutamol inhalation in acute asthma. Chest 1984; 86: 868-9.

16 Ros SP. Emergency management of childhood bronchial asthma: a multicenter survey. Ann Allergy 1991; 66: 231-4.

17 American Thoracic Society. Standards for the diagnosis and care of patients with chronic obstructive pulmonary disease (COPD) and asthma. Am Rev Respir Dis 1987; 136: $225-44$.

18 American Thoracic Society. Standardization of spirometry - 1987 update. Am Rev Respir Dis 1987; 136: 1285-98.

19 Tal A, Bavilski C, Yohai D, Bearman JE, Gorodischer R, Moses SW. Dexamethasone and salbutamol in the treatment of acute wheezing in infants. Pediatrics 1983; 71: 13-8.

20 Choo-Kang YFJ, Grant IWB. Comparison of two methods of administering bronchodilator aerosol to asthmatic patients. $B M \mathcal{F} 1975$; ii: 119-20.

21 Olivenstein R, Wolkove N, Cohen C, Frank H, Kreisman $H$. A comparison of responses to albuterol delivered by two aerosol devices. Chest 1986 ; $90: 392-5$.

22 Hodder RV, Calcutt LE, Leech JA. Metered dose inhaler with spacer is superior to wet nebulizer in acute asthma. Chest 1988; 94: $52 \mathrm{~S}$.

23 Mestitz H, Copland JM, McDonald CF. Comparison of outpatient nebulized vs metered dose inhaler terbutaline in chronic airflow obstruction. Chest 1989; 96: 1237-40.

24 Weber RW, Petty WE, Nelson HS. Aerosolized terbutaline in asthmatics. Comparison of dosage strength, schedule and method of administration. $\mathcal{f}$ Allergy Clin Immunol 1979; 63: 116-21.

25 Pederson JZ, Bungarrd A. Comparative efficacy of different methods of nebulizing salbutamol. Eur $\mathcal{f}$ Clin Pharmacol 1983; 25: 739-42.

26 Cushley MJ, Lewis RA, Tattersfield AE. Comparison of three techniques of inhalation on the airway response to terbutaline. Thorax 1983; 38: 908-13. 
27 Harris L. Comparison of the effect on blood gases, ventilation, and perfusion of isoproterenol-phenylephrine and tion, and perfusion of isoproterenol-phenylephrine and
salbutamol aerosols in chronic bronchitis with asthma. f Allergy Clin Immunol 1972; 49: 63-71.

28 Chick TW, Nicholson DP, Johnson RL. Effects of isoproterenol on distribution of ventilation and perfusion in

29 O'Callagh deterioration in lung function after nebulized salbutamo in wheezy infants. Lancet 1986; ii: 1424-5.

30 Desager KN, Bever HPV, Stevens WJ. Osmolality and pH of anti-asthmatic drug solutions. Agents Actions 1990; 31 $225-8$.

31 Schoni $\mathbf{M H}$, Kraemer R. Osmolality changes in nebulizer solutions. Eur Respir f 1989; 2: 887-92.

32 Goodall RIR, Gervis JE, Carper DN, Bernstein A, Temple JG. Relationship between asthma and gastro-oesophagea JG. Relationship between asthma

33 Schoeffel RE, Anderson SD, Altounyan REC. Bronchial hyperreactivity in response to inhalation of ultrasonically nebulised solutions of distilled water and saline. $B M^{9}$ 1981; 283: 1285-7. 34 Clay MM, Pavia D, Newman SP, Lennard-Jones T, Clarke $\mathrm{SW}$. Assessment of jet nebulisers for lung aerosol therapy. Lancet 1983; ii: 592-4.

35 Prendiville A, Rose A, Maxwell DL, Silverman M Hypoxaemia in wheezy infants after bronchodilator treatment. Arch Dis Child 1987; 62: 997-1000.

$36 \mathrm{Lin} \mathrm{YZ,} \mathrm{Hsieh} \mathrm{KH,} \mathrm{Shih} \mathrm{TY,} \mathrm{Chen} \mathrm{W,} \mathrm{Wu} \mathrm{KW.} \mathrm{Effects} \mathrm{of}$ terbutaline on oxygen saturation in acute asthmatic children. Acta Paediatr Sin 1994; 35: 377-83.

37 Tenholder MF, Bryson MJ, Whitlock WL. A model for conversion from small volume nebulizer to metered dose inhaler aerosol therapy. Chest 1992; 101: 634-7.

38 Bowton DL, Goldsmith WM, Haponik EF. Substitution of metered-dose inhalers for hand-held nebulizers: success and cost savings in a large, acute-care hospital. Chest 1992; 101: 305-8. 